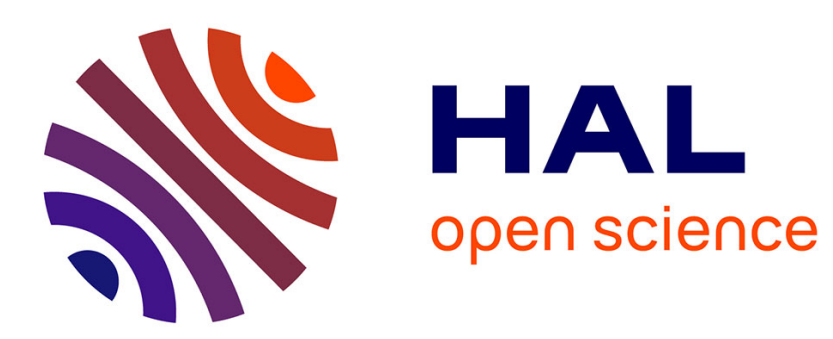

\title{
Influence of Copper Precursor on the Catalytic Transformation of Oleylamine during Cu Nanoparticles Synthesis
}

Antoine Pesesse, Sophie Carenco

\section{- To cite this version:}

Antoine Pesesse, Sophie Carenco. Influence of Copper Precursor on the Catalytic Transformation of Oleylamine during $\mathrm{Cu}$ Nanoparticles Synthesis. Catalysis Science \& Technology, 2021, 10.1039/D1CY00639H . hal-03273223

\section{HAL Id: hal-03273223 \\ https: / hal.sorbonne-universite.fr/hal-03273223}

Submitted on 29 Jun 2021

HAL is a multi-disciplinary open access archive for the deposit and dissemination of scientific research documents, whether they are published or not. The documents may come from teaching and research institutions in France or abroad, or from public or private research centers.
L'archive ouverte pluridisciplinaire HAL, est destinée au dépôt et à la diffusion de documents scientifiques de niveau recherche, publiés ou non, émanant des établissements d'enseignement et de recherche français ou étrangers, des laboratoires publics ou privés. 


\section{Influence of Copper Precursor on the Catalytic}

\section{Transformation of Oleylamine during $\mathrm{Cu}$ Nanoparticles \\ Synthesis}

Antoine Pesesse, ${ }^{1}$ Sophie Carenco ${ }^{1}$

${ }^{1}$ Sorbonne Université, CNRS, Collège de France, Laboratoire de Chimie de la Matière

Condensée de Paris, 4 place Jussieu, 75005 Paris, France

E-mail: sophie.carenco@ sorbonne-universite.fr 


\section{Abstract:}

For an optimal use of copper nanoparticles in catalysis, in-depth understanding of the reaction mechanisms and fine characterization of final products are equally relevant. Indeed, both have a direct impact on the nanoparticles core and surface. So far, most insights come from characterization techniques focusing on the inorganic component, i.e. the nanoparticle core. Molecular techniques are often overlooked and the reactions alongside the reduction of the copper precursor are not properly understood. This is detrimental to finely interpret the nanoparticles behavior in catalytic processes. Here, copper nanoparticles synthesis was studied by thorough characterization of the organic reactions happening during the synthesis, quantitatively by ${ }^{1} \mathrm{H}$ Nuclear Magnetic Resonance $\left({ }^{1} \mathrm{H}\right.$ NMR) and qualitatively by infra-red spectroscopy (IR) and electrospray ionisation-mass spectrometry (ESI-MS). The reduction of copper(II) acetate $\left(\mathrm{Cu}(\mathrm{OAc})_{2}\right)$ by oleylamine resulted in high amount of water and few byproducts while the reduction of copper(II) acetylacetonate $\left(\mathrm{Cu}(\mathrm{acac})_{2}\right)$ resulted in low amount of water and many products. The resulting nanoparticles showed a different ability to further dehydrogenate and transaminate oleylamine in the synthesis reaction pot. This was explained by the presence of a copper oxide phase in the nanoparticles prepared from copper acetate.

Keywords: copper nanoparticles, oleylamine, reaction mechanism, reaction byproducts, dehydrogenation, transamination. 


\section{Introduction}

Metal-containing nanoparticles are complex objects composed of an inorganic core, an inorganic surface and an organic shell. Each component of the nanoparticles has an influence on the nanoparticle properties. The inorganic core governs band gap ${ }^{1}$, plasmonic properties, ${ }^{2}$ and melting temperature ${ }^{3}$ while the inorganic surface and the organic shell control ageing, ${ }^{4}$ colloidal stability ${ }^{5}$ and catalytic activity. ${ }^{6,7}$ Rational colloidal synthesis of nanoparticles is key to obtain fine-tuned object, in particular regarding their surface. However, most studies about nanoparticle synthesis focus on the inorganic component of the metal nanoparticles (the core). For example, the molecular process leading to the formation of nanoparticles, i.e. the reduction of the metal center or the formation of M-O-M bonds are the most studied, with a focus on inorganic characterization of the final nanoparticles.

Fewer works concern the molecular component (the ligand shell) around the inorganic core. This shell is critical regarding the colloidal stability, the ageing and the catalytic properties of the nanoparticles. It forms from the ligands introduced in the reaction mixture. However, these ligands may also react with the metal precursor and transform in other species. Besides, the side reactions happening alongside the nucleation and growth can influence the nanoparticles crystallinity, composition and shape. Detailed analysis of the molecular species in the reaction medium using infra-red (IR), UV and nuclear magnetic resonance spectroscopy (NMR) spectroscopies, and mass spectrometry (MS), allow understanding reactions between solvent and metal precursor, the ligands exchange and the side reactions with the solvent. For example, Niedeberger et al. explained the formation of two phases, maghemite $\mathrm{Fe}_{2} \mathrm{O}_{3}$ and magnetite $\mathrm{Fe}_{3} \mathrm{O}_{4}$, from benzylamine and $\mathrm{Fe}(\mathrm{acac})_{3}(\mathrm{acac}=$ acetylacetonate $)$, by analyzing the organic side-reactions. ${ }^{8}$ Hens et al. unravelled the presence of a $\mathrm{Cu}_{2} \mathrm{O}$ phase at the surface of $\mathrm{Cu}$ nanoparticles by studying the exchange of oleylamine by undecanoïc acid. Using ${ }^{1} \mathrm{H}$ NMR and IR, they showed that carboxylic acid binds in a dissociative manner on the $\mathrm{Cu}_{2} \mathrm{O}$ surface. ${ }^{9}$ 
Reactions of ligands with other compounds in the reaction mixture can control the nature of the organic shell. Niederberger et al. showed that the reduction of Mo(+VI) precursor by benzyl alcohol led to the formation of $\mathrm{MoO}_{2}$ and benzoic acid that coordinates the newly formed nanoparticles and influences the nanoparticles morphology. ${ }^{10}$

Oleylamine is a ubiquitous reactant in colloidal synthesis. Its role during the reduction of the metal precursor was well studied. In the case of cobalt nanoparticles prepared from phosphine-stabilised $\mathrm{Co}(\mathrm{I})$ precursors, oleylamine only promoted the dismutation of the $\mathrm{Co}(\mathrm{I}) .{ }^{11}$ Our group showed that a rich reactivity between, metal(II) acetylacetonate complex, (( $\mathrm{M}(\mathrm{acac})_{2}$ or $\left.\mathrm{M}\left(\mathrm{C}_{5} \mathrm{H}_{7} \mathrm{O}_{2}\right)_{2}\right)$ and oleylamine happens during $\mathrm{Ni}$ and $\mathrm{Pd}$ nanoparticles synthesis, where the oleylamine acts as the reducing agent through oxidative dehydrogenation. ${ }^{12}$

Regarding the synthesis of $\mathrm{Cu}$ nanoparticles by reduction of $\mathrm{Cu}(\mathrm{acac})_{2}$ with oleylamine, we recently showed that oleylamine was not the ligand of the nanoparticles. Rather, the ligand was a species formed during the reaction: $N$-oleylacetamide. Because the oleylamine was introduced in a large excess, it was unclear how much was consumed. Moreover, because the acetylacetonate ligand was condensing on oleylamine, the influence of the metal precursor was unclear.

In this work, we designed an experimental strategy to answer these questions: first, by comparing $\mathrm{Cu}(\mathrm{acac})_{2}$ with another $\mathrm{Cu}(\mathrm{II})$ precursor, copper(II) acetate $\left(\mathrm{Cu}(\mathrm{OAc})_{2}\right.$ or $\left.\mathrm{Cu}\left(\mathrm{CH}_{3} \mathrm{CO}_{2}\right)_{2}\right)$, and second, by investigating the reaction of oleylamine with preformed copper based nanoparticles. Infrared spectroscopy, mass spectrometry and proton nuclear magnetic resonance, both at the end and on aliquots sampled during the synthesis, were used to identify the synthesis byproducts. As expected, both syntheses resulted in the formation of $\mathrm{Cu}(0)$ phase as the major species. However, the formation of an additional phase of copper oxide occured in variable amounts when $\mathrm{Cu}(\mathrm{OAc})_{2}$ was used, which was rationalized in relation with the amount of water formed. In addition, the two syntheses resulted in different 
organic byproduct mixtures. Catalytic transformation of oleylamine by the isolated nanoparticles was then performed. Nanoparticles from $\mathrm{Cu}(\mathrm{OAc})_{2}$ catalysed the formation of a single dehydrogenation byproduct with a low conversion of oleylamine, while nanoparticles from $\mathrm{Cu}(\mathrm{acac})_{2}$ catalysed the formation of many dehydrogenation and transamination byproducts with a high conversion of oleylamine. The presence of oxide in nanoparticles from $\mathrm{Cu}(\mathrm{OAc})_{2}$ explains the difference in nanoparticles activity, and the different amount of chemical species formed during the synthesis.

\section{Results}

\subsection{Characterization of the inorganic particles}

Copper nanoparticles were synthetized by adapting a procedure from our group. ${ }^{13}$ Shortly, 1 eq. of $\mathrm{Cu}(\mathrm{OAc})_{2}$ or $\mathrm{Cu}(\mathrm{acac})_{2}$ was mixed with 10 eq. of degazed oleylamine and heated at $250{ }^{\circ} \mathrm{C}$ during 2 hours under inert atmosphere The nanoparticles were separated from the reaction mixture by centrifugation and washing in air or under inert atmosphere (see details in part 5.1, 5.2 and 5.3 of experimental section). Synthesis with $\mathrm{Cu}(\mathrm{OAc})_{2}$ and $\mathrm{Cu}(\mathrm{acac})_{2}$ will be referred as $\boldsymbol{A}$ and $\boldsymbol{B}$, while formed nanoparticles will be referred as $\boldsymbol{C} \boldsymbol{u}_{-} \boldsymbol{A}$ and $\boldsymbol{C} \boldsymbol{u} \_\boldsymbol{B}$. The powders obtained after washing in air were characterised by transmission electron microscopy (TEM) and by X-ray diffraction (XRD). TEM after washing shows that $\boldsymbol{C} \boldsymbol{u} \_\boldsymbol{A}$ is composed of aggregated nanoparticles and $\boldsymbol{C} \boldsymbol{u} \_\boldsymbol{B}$ is composed of polydisperse nanoparticles of $50 \pm 10 \mathrm{~nm}$ (Figure 1b,c). TEM micrograph of $\boldsymbol{C} \boldsymbol{u}_{-} \boldsymbol{A}$ before washing (Figure S1) confirmed that the aggregated solid was formed of particle of nanometric size.

XRD patterns in Figure 1a show that both $\underline{\boldsymbol{C u} \_\boldsymbol{A}}$ and $\boldsymbol{C} \boldsymbol{u}_{-} \boldsymbol{B}$ contain $\mathrm{Cu}(0)$ with Scherrer crystal sizes of respectively 30 and $20 \mathrm{~nm}$. In $\boldsymbol{C} \boldsymbol{u} \_\boldsymbol{A}, \mathrm{Cu}_{2} \mathrm{O}$ was detected in varying amounts: as traces (signal/noise $=4$ ) in some samples and as main product in others. XRD pattern of other $\boldsymbol{C} \boldsymbol{u}_{-} \boldsymbol{A}$ samples, prepared with the same procedure but showing different amount of 
oxide, are plotted in Figure S2. Crystal size for oxide phase of the sample shown is $45 \mathrm{~nm}$. In contrast with this result, $\boldsymbol{C} \boldsymbol{u} \_\boldsymbol{B}$ samples never contained more than traces (signal/noise $=5$ ) of $\mathrm{Cu}_{2} \mathrm{O}$ with Scherrer size below $5 \mathrm{~nm}$.

We hypothesize that for $\boldsymbol{C} \boldsymbol{u}_{-} \boldsymbol{B}$, oxide formation is due to air exposure during XRD analysis. A dedicated study on thin films estimated the thickness of the passivation layer to be around $3 \mathrm{~nm}$ for a $48 \mathrm{~h}$ air exposure using Extended X-Ray Absorption Fine Structure at grazing angles. This is consistent with the observed Scherrer size of $\mathrm{Cu}_{2} \mathrm{O}$, which is below $5 \mathrm{~nm}$.

For $\boldsymbol{C} \boldsymbol{u}_{-} \boldsymbol{A}$, the $45 \mathrm{~nm}$-wide $\mathrm{Cu}_{2} \mathrm{O}$ is too thick to explain its formation by air exposure only. Thus we can conclude that the oxide phase was mainly formed in the reaction medium at elevated temperature.

To understand why such different phases were obtained in syntheses $\boldsymbol{A}$ and $\boldsymbol{B}$, and the variability in synthesis $\boldsymbol{A}$, the molecular processes happening during the reaction were investigated. 


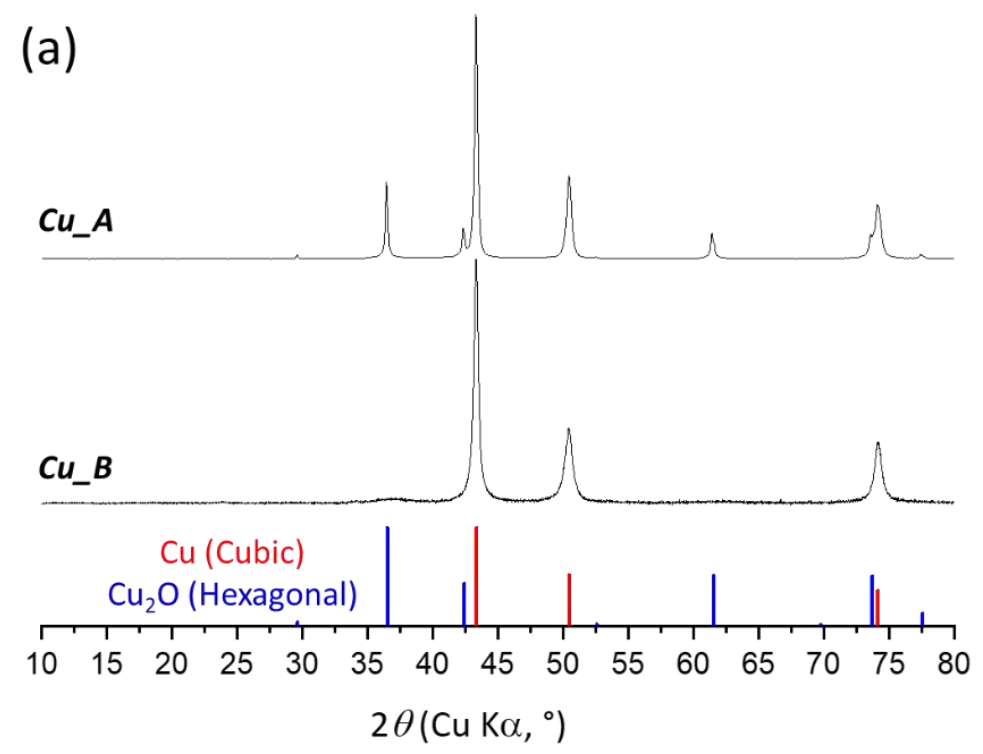

(b)

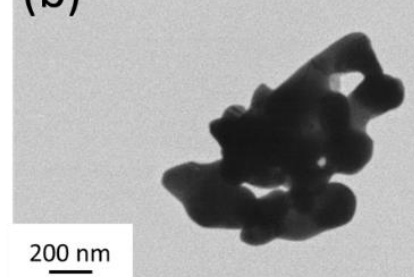

(c)

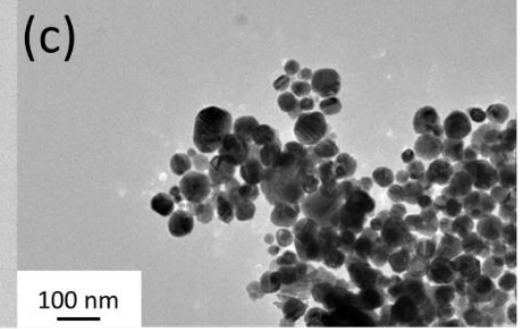

Figure 1: (a) XRD pattern of copper nanoparticles, $C U_{-} A$ synthesized with $\mathrm{Cu}(\mathrm{OAc})_{2}$ as precursor and $\mathrm{Cu} \_B$ with $\mathrm{Cu}(\mathrm{acac})_{2}$. XRD reference pattern for cubic $\mathrm{Cu}$ in red (COD number: 9008468$)$ and for cubic $\mathrm{Cu}_{2} \mathrm{O}$ in blue (COD number: 1010941) (bottom). (b), (c) TEM micrographs of copper nanoparticles $C u \_A$ and $C u \_B$, respectively

\subsection{Molecular byproducts of the two reactions}

\section{Identification of the molecular species present at the end of the syntheses}

Proton nuclear magnetic resonance $\left({ }^{1} \mathrm{H}\right.$ NMR) spectroscopy, infrared (IR) spectroscopy and electron spray ionization mass spectrometry (ESI-MS) were used to identify the molecular species produced during the syntheses. Molecular species discussed below are numbered in Figure 2. 

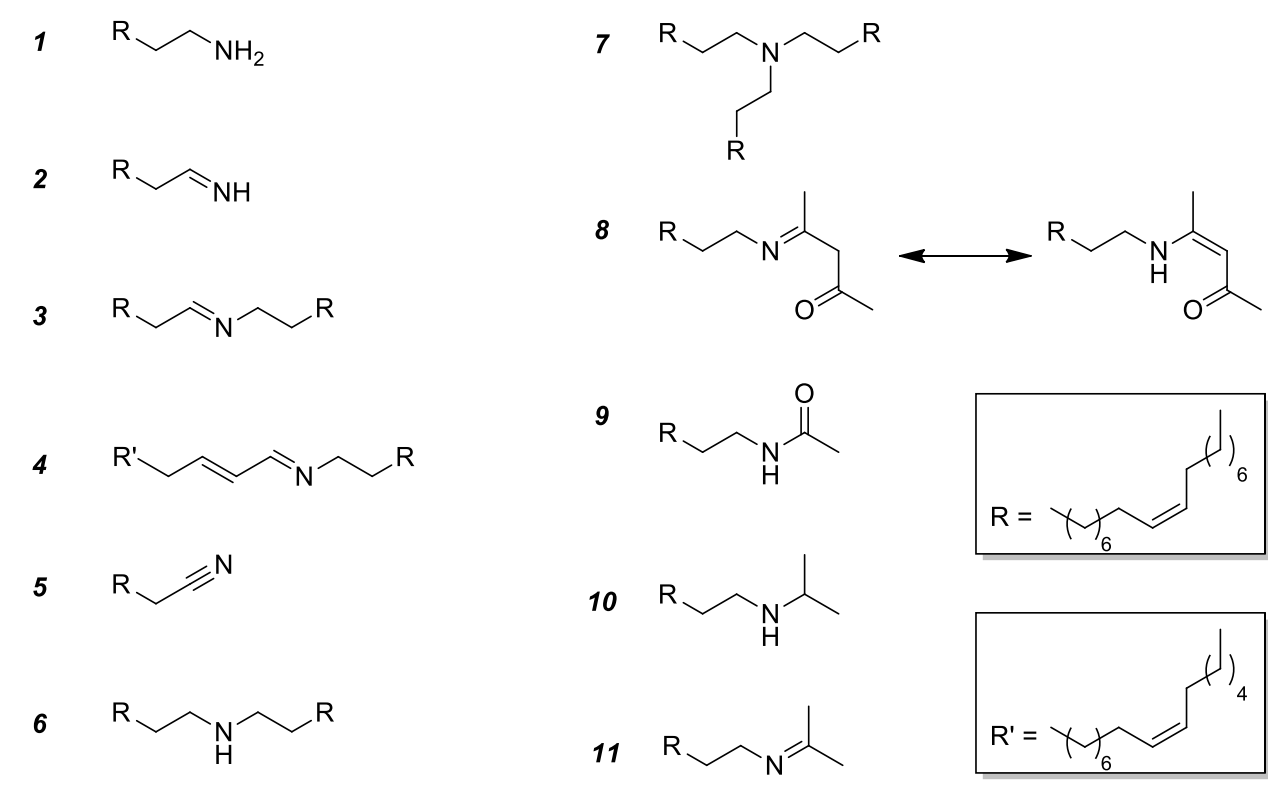

9<smiles>[R]CCNC(C)=O</smiles>

10<smiles>[R]CCNC(C)C</smiles>

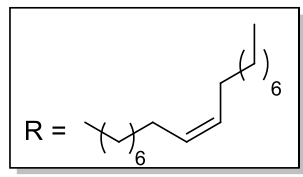

Figure 2: Simplified nomenclature adopted in this study.

IR spectra, ${ }^{1} \mathrm{H}$ NMR spectra and ESI-MS of the supernatant of synthesis $\boldsymbol{A}$ are given in Figure 3, Figure S4 and Figure S5. Three products were detected. For sake of comparison, ${ }^{1} \mathrm{H}$ NMR spectrum of commercial oleylamine is shown in Figure S3. Remaining oleylamine 1 was detected on ${ }^{1} \mathrm{H}$ NMR by a triplet at $2.66 \mathrm{ppm}$ and a wide signal at $1.16 \mathrm{ppm}$, on IR by a band at $790 \mathrm{~cm}^{-1}$ corresponding to $\mathrm{NH}_{2}$ bending vibration and in MS by a peak at $268.2998 \mathrm{~m} / \mathrm{z}$ (Table S1, entry B). The formation of $N$-oleylacetamide 9 was evidenced by ${ }^{1} \mathrm{H}$ NMR by a singlet at $1.95 \mathrm{ppm}$, a quadruplet at $3.21 \mathrm{ppm}$ and a broad signal at $5.53 \mathrm{ppm}$. This result was confirmed by the detection of a peak at $310.3102 \mathrm{~m} / \mathrm{z}$ in the MS spectrum (Table S1, entry D) and by the presence of two bands characteristic of an amide: the $\mathrm{C}=\mathrm{O}$ bond and $\mathrm{N}-\mathrm{H}$ bond bending at $1660 \mathrm{~cm}^{-1}$ and $1620 \mathrm{~cm}^{-1}$, respectively. Moreover, on the NMR ${ }^{1} \mathrm{H}$ spectrum, a quadruplet at $2.21 \mathrm{ppm}$ and two triplets at $3.32 \mathrm{ppm}$ and $7.65 \mathrm{ppm}$ suggested the formation of the secondary aldimine 3, containing the oleyl fragment. A peak at $516.5498 \mathrm{~m} / \mathrm{z}$ in the MS spectrum (Table S1, entry E) confirmed this hypothesis. In the IR spectrum, the slight shoulder at $1670 \mathrm{~cm}^{-1}$, below the on $\mathrm{C}=\mathrm{O}$ bond stretching band at $1660 \mathrm{~cm}^{-1}$, could 
correspond to the $\mathrm{C}=\mathrm{N}$ bond streching band of this secondary imine. Two unexpected peaks at 559.5920 and $577.6026 \mathrm{~m} / \mathrm{z}$ were detected in the mass spectrogram (Table S1, entries $\mathrm{F}$ and G). The product at $559.5920 \mathrm{~m} / \mathrm{z}$ can be interpreted as a product formed from the condensation of 1 on $\mathbf{9}$. We propose that this product was formed during the ESI-MS analysis, because no evidence of its presence was found in the ${ }^{1} \mathrm{H}$ NMR spectrum. The products at $577.6026 \mathrm{~m} / \mathrm{z}$ could correspond to the same compound in weak interaction with a water molecule.

IR spectra, ${ }^{1} \mathrm{H}$ NMR spectra and ESI-MS of the supernatant of synthesis $\boldsymbol{B}$ are given in Figure 3, Figure S6 and Figure S7 shows that for synthesis $\boldsymbol{B}$ more products were obtained than for synthesis $\boldsymbol{A}$. As for synthesis $\boldsymbol{A}$, oleylamine $\mathbf{1}$, amide $\mathbf{9}$ and secondary aldimine $\mathbf{3}$ were detected. Triplet in the ${ }^{1} \mathrm{H}$ NMR at $2.56 \mathrm{ppm}$, a band in the IR spectrum at $1130 \mathrm{~cm}^{-1}$ characteristics of a secondary amine C-N bound bending and a peak at $518.56522 \mathrm{~m} / \mathrm{z}$ in the mass spectrum (Table S2, entry I) showed the presence of secondary amine 6 formed by the transamination of two equivalents of 1. Similarly, a triplet at $2.37 \mathrm{ppm}$ in ${ }^{1} \mathrm{H} \mathrm{NMR}$ spectrometry, a band characteristic of tertiary amine C-N bond bending at $1085 \mathrm{~cm}^{-1}$ in IR spectrometry demonstrate the formation of the tertiary amine 7 issued from the transamination of three equivalents of 1 . The formation of nitrile 5 formed by dehydrogenation of oleylamine was shown by a triplet at $2.34 \mathrm{ppm}$ by ${ }^{1} \mathrm{H}$ NMR spectrometry and a band characteristics of $\mathrm{C} \equiv \mathrm{N}$ bond stretching at $2250 \mathrm{~cm}^{-1}$. No signal was found in MS corresponding to 5 , likely because the nitrile moiety is hard to ionize. A doublet at $1.04 \mathrm{ppm}$ in ${ }^{1} \mathrm{H}$ NMR and a peak at $310.3464 \mathrm{~m} / \mathrm{z}$ (Table S2, entry F) indicated the formation of the $\mathrm{N}$-isopropyloleylamine 10 . A peak at $368.3630 \mathrm{~m} / \mathrm{z}$ (Table $\mathrm{S} 2$, entry H) in MS suggested the formation of the keto-eneoleylamine $\boldsymbol{8}$ derived from the condensation of $\boldsymbol{1}$ on acetylacetone. However, no clear signature of 8 was found in the IR and ${ }^{1} \mathrm{H}$ NMR spectra. Finally, the presence of primary imine 2 issued from the dehydrogenation of oleylamine is indirectly suggested. Quadruplets in 
the 2.13-2.23 ppm region are characteristics of $\mathrm{CH}_{2}$ protons in alpha of $\mathrm{C}$ of imine $\mathrm{C}=\mathrm{N}$ bond or $\mathrm{C}=\mathrm{C}$ bond conjugated to $\mathrm{C}=\mathrm{N}$ imine bond while the triplet at $3.33 \mathrm{ppm}$ is characteristic of $\mathrm{CH}_{2}$ protons in alpha of an imine. The fact that integration of the first was higher than of the latter indicated that the primary imine 2 is present. No others proof could be found to confirm this claim. Others low intensity peaks were not attributed.

(A) $\quad 1 \quad \mathrm{R} \smile \mathrm{NH}_{2}$

(B)

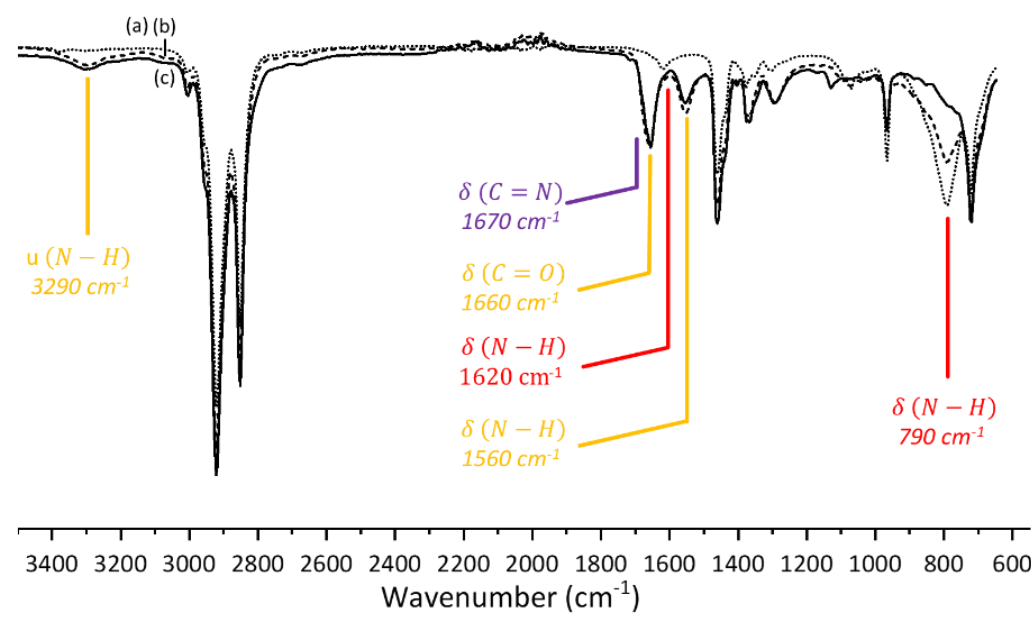

(C)

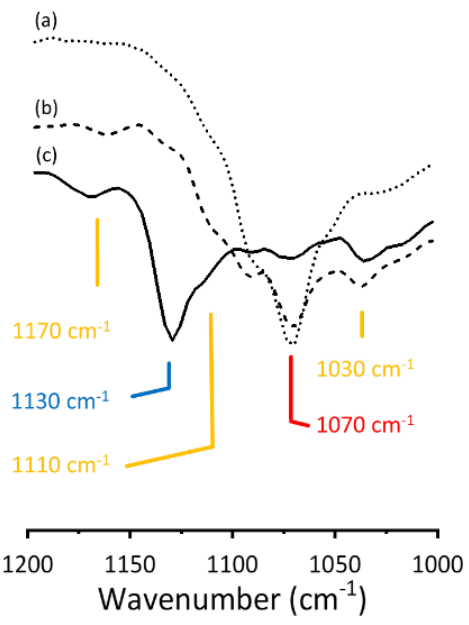

Figure 3: (A) Molecular structure of the species for which characteristic signals were detected by IR spectroscopy (B) IR spectrum of (a) Commercial oleylamine, (b,c) Reaction crude of syntheses $A$ and $B$, respectively (C) Zoom in the carbon nitrogen simple bound stretching region (all the band attributed correspond to carbon nitrogen simple bound stretching). The colours of the line used to attribute the IR spectra band in (B), (C) refer to same coloured molecular structure in (A)

\section{Semi-quantitative analysis of the byproducts in syntheses $A$ and $B$}

Yields were calculated using ${ }^{1} \mathrm{H}$ NMR for reactions $\boldsymbol{A}$ and $\boldsymbol{B}$ and are given in Table 1. The copper nanoparticles widen some signals of the molecules that interact with them. It leads to underestimate the corresponding integration. For the following analysis, we made the hypothesis that the only signals affected by this bias are these from oleylamine, as this was the simpler way to proceed. In others words, all the missing signals (in terms of cumulated integration) were attributed to oleylamine. This procedure still allows for a semi-quantitative analysis of the byproducts. Experimental evidence for this hypothesis will be given below. 


\begin{tabular}{|c|c|c|c|c|c|}
\hline & Species & $A(\%)$ & $A^{\prime}(\%)$ & $B(\%)$ & $B^{\prime}(\%)$ \\
\hline 3 & Secondary aldimine & 5 & 5 & 10 & Traces \\
\hline 4 & Conjugated secondary aldimine & & 5 & & 5 \\
\hline 2 & Primary imine & & & 5 & 5 \\
\hline 5 & Nitrile & & & Traces-5 & 5 \\
\hline 6 & Secondary amine & & & 25 & 10 \\
\hline 7 & Tertiary amine & & & $<5$ & 15 \\
\hline 9 & Amide & 20 & 20 & 20 & 20 \\
\hline \multirow[t]{2}{*}{10} & $\mathrm{~N}$-isopropylamine & & & Traces-5 & \\
\hline & Conversion & 25 & 30 & $70-80$ & 60 \\
\hline
\end{tabular}

Table $1:{ }^{1} \mathrm{H}$ NMR yield and oleylamine conversion (percent of initial product consumed) for synthesis $A, A$ ', $B$ and $B^{\prime}$.

"Traces" means that ${ }^{1} \mathrm{H}$ NMR yield was well below $5 \%$.

In both reactions, products 3 and 9 are formed in similar yields. However, the remaining amount of oleylamine was higher in $\boldsymbol{A}$ (about $75 \%$ ) and lower in $\boldsymbol{B}$ (below $30 \%$ ). In relation with this, reaction $\mathrm{B}$ led to the formation of additional molecular species $5,6,7$ and 10 , all with yields below $25 \%$. None of these new products, except 10, can be explained by moving from OAc to acac moieties. To gather more information on the formation of these products, the syntheses were followed by ${ }^{1} \mathrm{H}$ NMR by taking aliquots from the reaction medium during the heating ramp and plateau (see details in the part 5.5 of the experimental section)

\section{Monitoring of the organic byproducts during synthesis $A$ and $B$}

${ }^{1} \mathrm{H}$ NMR shown in Figures S8a, S8b, S8c and ${ }^{1} \mathrm{H}$ NMR yield in Table 1 show that products found for monitored synthesis $\boldsymbol{A}$ (named $\boldsymbol{A}^{\prime}$ ) and regular synthesis $\boldsymbol{A}$ were identical and formed with fairly similar yield. XRD pattern (Figure S10a) and TEM micrograph (Figure $\mathrm{S} 10 \mathrm{~b})$ of the obtained nanoparticles were very similar to those obtained for the regular synthesis $\boldsymbol{A}$ (Figure 1). A slightly larger, Scherrer size of $40 \mathrm{~nm}$ for metallic copper was found.

Two additional signals were observed: a doublet at $7.33 \mathrm{ppm}$ and a quadruplet at $2.15 \mathrm{ppm}$ that were attributed to the formation of the conjugated secondary aldimine 4 . Comparison of successive aliquots provided insights on the sequence of product formation. The amide 9 was 
first detected at $170{ }^{\circ} \mathrm{C}$ and $90 \%$ of its formation happened during the heating ramp. The secondary aldimine 3 first appeared at $200{ }^{\circ} \mathrm{C}$ and increased till $1 \mathrm{~h}$ of reaction. Finally, the formation of conjugated secondary aldimine $\mathbf{4}$ happened during the last hour of reaction. Its formation was concurrent to the consumption of secondary imine 3 . This suggests that 4 was formed from 3 .

${ }^{1} \mathrm{H}$ NMR spectra in Figures S9a, S9b, S9c and ${ }^{1} \mathrm{H}$ NMR yield in Table 1 show that monitored synthesis $\boldsymbol{B}$ (named $\boldsymbol{B}^{\prime}$ ) gave products and proportion that falls into the range observed for regular synthesis $\boldsymbol{B}$. XRD pattern (Figure S10a) and TEM (Figure S10c) of obtained nanoparticles were slightly different from $\boldsymbol{C} \boldsymbol{u} \_\boldsymbol{B}$. The Scherrer size of metallic copper was roughly the same: $25 \mathrm{~nm}$. However, a $\mathrm{CuO}$ oxide phase was detected. High temperature is known to foster the formation of $\mathrm{CuO}$ by oxidation of metallic copper by molecular oxygen. ${ }^{15}$ We can infer that oxygen entering during sampling is responsible for its formation. This phenomenon was certainly also happening in $\boldsymbol{C} \boldsymbol{u}_{-} \boldsymbol{A}$ synthesis. However due to the large size or difference of organic shell nature of the nanoparticles in $\boldsymbol{C} \boldsymbol{u} \_\boldsymbol{A}$, it is possible that the $\mathrm{CuO}$ phase was thinner, making it not detectable by XRD. Moreover, TEM micrograph (Figure S10c) shows the formation of some nanoparticles of size below $10 \mathrm{~nm}$. A hypothesis to explain their formation would be that there are formed by the leaching of the copper oxide phase. The only new product was the conjugated secondary aldimine 4 also observed in

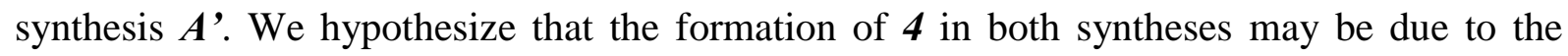
presence of the $\mathrm{CuO}$ phase.

Many products were formed during the heating ramp. The amide 9 was first detected at $170{ }^{\circ} \mathrm{C}$ and $100 \%$ of its formation happened during the heating ramp. A singlet at $10.86 \mathrm{ppm}$ was detected, and could be attributed to the proton borne by a nitrogen either in the imine moiety of primary imine 2 or in the enamine moiety of keto-ene-amine 8 . However, if primary imine 2 was formed, a signal should have appeared in 7.3-7.7 ppm region. The absence of 
such signal confirms the formation of 8 . Acetone formation was evidenced from the apparition of characteristics singlets at $2.16 \mathrm{ppm}$. Many other singlets at 1.80, 1.85, 1.9, 4.94 ppm were detected and could not be precisely attributed. The singlet multiplicity of theses protons indicates a molecular structure where the carbon in beta position of them doesn't bear any protons themselves. Knowing that oleylamine 1 and $\mathrm{Cu}(\mathrm{acac})_{2}$ are the only species introduced in the reaction medium, that such kinds of molecular structure cannot come from oleylamine reaction with itself and that the acacH moiety is not likely to self-react and finally that the only final product formed from the reaction of oleylamine 1 and $\mathrm{Cu}(\mathrm{acac})_{2}$ in the heating ramp is the amide 9 , we propose that these compounds, as well as acetone and ketoneene-amine 8 , are intermediates of reaction between oleylamine 1 and $\mathrm{Cu}(\mathrm{acac})_{2}$ leading to amide 9.

The nitrile 5, the secondary amine 6 and the tertiary amine 7 were first detected after 30 min of plateau and, after 1 hour of reaction, their quantity reached respectively $90 \%, 100 \%$ and $100 \%$ of their final amount. Primary imine 2 started to form at $170{ }^{\circ} \mathrm{C}$. Its quantity fluctuated during the whole reaction and reached back its value at $170{ }^{\circ} \mathrm{C}$ at the end. This suggested that this imine plays the role of a reaction intermediate. The amount of secondary aldimine 3 started to rise at $200{ }^{\circ} \mathrm{C}$, was maximal after 30 min of plateau and decreased till the end of the reaction, while the quantity of conjugated secondary imine 4 increased from 30 min of plateau till the end. This suggests that 4 was produced from 3 , as in synthesis $\boldsymbol{A}$.

\section{About the origin of copper oxide in $C u \_A$}

We propose that the elementary steps involved in the formation of amide 9 , observed in both syntheses, are responsible for the formation of nanoparticles with different inorganic nature. In the following paragraph, we write these steps from acetic acid and acetylacetone, rather than from acetate and acetylacetonate coordinated to copper center. This is a simplified way 
to visualize the outcome of each organic fragment or moiety. In the reaction flask, the copper center is much likely involved in the formation of $\mathbf{9}$ but this is out of the scope of this study because it is not relevant to the following analysis by fragments. Such approach, neglecting the metal center, was already used with success in the case of $\mathrm{Ni}(\mathrm{acac})_{2}$ reaction with oleylamine. $^{16}$

In the case of synthesis $\boldsymbol{A}$, product $\boldsymbol{9}$ is formed by the easy addition of oleylamine $\boldsymbol{1}$ on acetic acid and water elimination (Figure 4a).

In the case of synthesis $\boldsymbol{B}$, there are two pathways for the formation of $\boldsymbol{9}$ described in Figure 4b. Either the addition of oleylamine 1 on acetylacetone directly forms the amide 9 and acetone, or 1 condensates on the acetylacetone to form the ketone-ene-amine 10 and water. Then a second equivalent of $\boldsymbol{1}$ is added to break the $\mathrm{C}-\mathrm{C}$ bond of acetylacetone and form amide 9 and the secondary enamine 11. 11 will be further hydrogenated and detected as secondary amine $\mathbf{1 0}$.

Experimental results show that both pathways occur. The formation of acetone during the heating ramp of synthesis $\boldsymbol{B}$ '. A similar pathway was proposed by the group of Niederberger in the case of $\mathrm{Cu}(0)$ nanoparticles synthesis from benzyl alcohol and $\mathrm{Cu}(\mathrm{acac})_{2} \cdot{ }^{17}$ In this work, benzyl alcohol and acetylacetone react together to form the corresponding ester and acetone. Besides, pathway 2 is supported by the detection of 0.2 to 0.3 eq. of the secondary amine 10 in the reaction crude by ${ }^{1} \mathrm{H}$ NMR and the detection of signals characteristics of ketone-ene-amine 8 during synthesis $B$ '. From the quantification of secondary amine 10, we can conclude that 1.7 to 1.8 eq. of amide 9 was formed via pathway 1 while 0.2 to 0.3 eq. of amide 9 was formed via pathway 2. 

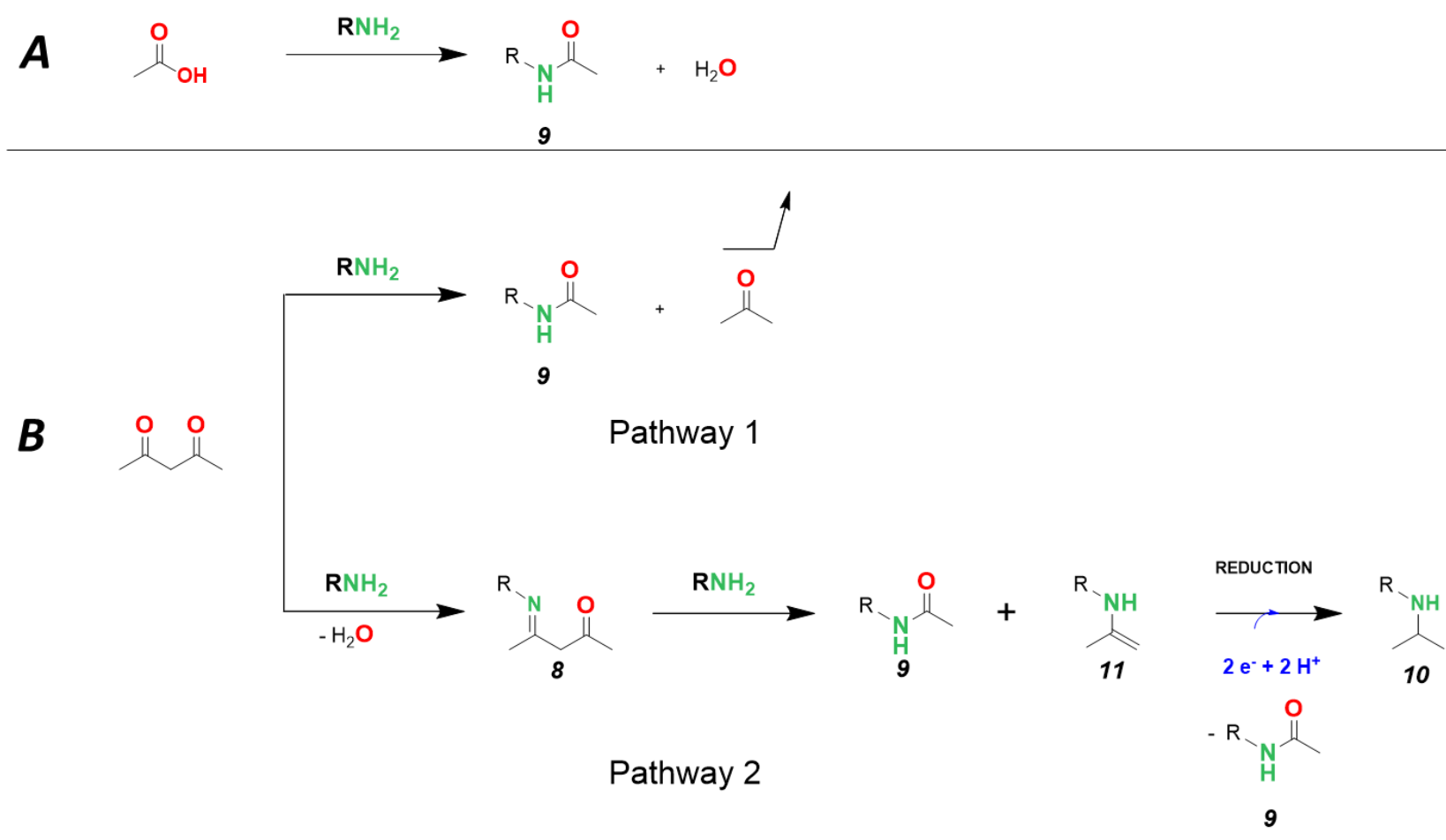

Figure 4 : Reaction mechanism for the formation of amide 5 from oleylamine 1 and (a) acetic acid and (b) acetylacetone respectively in syntheses $A$ and $B$.

The two proposed reaction mechanisms lead to different amounts of produced water: 2 eq. for synthesis $\boldsymbol{A}$ and 0.2-0.3 eq. for synthesis $\boldsymbol{B}$. Water is likely to react with the copper(0) surface atom to form $\mathrm{Cu}(+\mathrm{I})$ or $\mathrm{Cu}(+\mathrm{II})$ by oxidation and/or hydroxylation. Water was already proven to be an oxygen supplier in the synthesis of $\mathrm{Fe}_{3} \mathrm{O}_{4}$ nanoparticles from $\mathrm{Fe}(\mathrm{acac})_{3}{ }^{18}$ Thus the difference in the quantity of produced water could explain why $\boldsymbol{C} \boldsymbol{u} \_\boldsymbol{A}$ and $\boldsymbol{C} \boldsymbol{u} \_\boldsymbol{B}$ have different inorganic nature, i.e. containing some oxidised copper in the case of $\boldsymbol{C} \boldsymbol{u} \_\boldsymbol{A}$ and containing $\mathrm{Cu}(0)$ in the case of $\boldsymbol{C} \boldsymbol{u}_{-} \boldsymbol{B}$.

It remained to be explained why such different quantities of oxide are obtained for different sample of $\boldsymbol{C} \boldsymbol{u} \_\boldsymbol{A}$. A nitrogen flux is used to keep the reaction medium under inert atmosphere. This nitrogen flux can take out gaseous water from the reaction pot. Variation in the nitrogen flow intensity would lead to variation of water quantity in the medium and thus of copper oxide formed. 
To confirm this hypothesis, water was purposely removed from the reaction medium by modifying the experimental procedure of synthesis $\boldsymbol{A}$. The reaction medium was heated at $160{ }^{\circ} \mathrm{C}$ during 30 minutes to allow the formation of amide 9 and water from acetic acid and oleylamine. Then the reaction was cooled down to $60{ }^{\circ} \mathrm{C}$ and degassed during 30 minutes to extract water from the medium. The reaction process was then finished as in regular synthesis A. XRD analysis performed on the isolated powder shows only peaks corresponding to metallic copper nanoparticles with a Scherrer crystal size of $40 \mathrm{~nm}$, slightly larger than for regular synthesis $\boldsymbol{A}$. However, no peak corresponding to copper oxide was detected (Figure S12). The TEM micrograph in Figure S12 shows nanoparticles similar as $\boldsymbol{C} \boldsymbol{u} \_$. This confirms the role of water produced in the reaction medium on the formation of copper oxide, which can be prevented by evacuating it during the synthesis.

\section{About the nature of byproducts in syntheses $A$ and $B$}

Going back to the molecular species formed, we still need to explain why species not parent to acetic acid and acetylacetonate formed in synthesis $\boldsymbol{B}$ while these were absent in synthesis $\boldsymbol{A}$. We noticed that these species, nitrile 5 , secondary amine 6 and tertiary amine 7 were formed after the reaction reached its plateau of temperature, i.e. once nanoparticles were present in the medium. We hypothesise that their formation was catalysed by formed nanoparticles. The difference of size and nature $\boldsymbol{C} \boldsymbol{u} \_\boldsymbol{A}$ and $\boldsymbol{C} \boldsymbol{u} \_\boldsymbol{B}$ could explain why $\mathbf{5 , \boldsymbol { 6 }}$ and $\boldsymbol{7}$ are produced in synthesis $\boldsymbol{B}$ and not in $\boldsymbol{A}$. In order to test this hypothesis, we attempted catalytic reactions of fresh oleylamine with the isolated nanoparticles.

\section{Catalytic transformation of oleylamine with $C u_{-} A$ and $C u_{-} B$}

Observations discussed above suggested that oleylamine, as well as the other amines byproducts, may be reacting with $\mathrm{Cu}$ based nanoparticles formed._Another argument advocates for the strong surface interaction of oleylamine with the surface of $\mathrm{Cu}$

nanoparticles. Indeed, ${ }^{1} \mathrm{H}$ NMR spectroscopy of the reaction crude of synthesis $\boldsymbol{B}$ before 
centrifugation (Figure S12a): shows that the signals obtained for oleylamine 1 and secondary amine 6 are especially broad, compared with these of the same solution from which the nanoparticles were removed by centrifugation (Figure S12b). For $\mathbf{1}$, the signal is so wide it cannot be seen before centrifugation. This widening shows that $\boldsymbol{C} \boldsymbol{u}_{-} \boldsymbol{B}$ intimately interact with 1 and 6. We attempted catalytic reaction with fresh oleylamine to test our hypothesis.

We know from the nanoparticles characterization that their surface is rapidly oxidized under air. Thus, we tested first the influence of air exposure on the catalytic activity of nanoparticles. Transformation of oleylamine 1 in neat conditions was performed using 0.2 eq. of copper nanoparticles at $250{ }^{\circ} \mathrm{C}$ (see details in part 5.6 of the experimental section). Nanoparticles $\boldsymbol{C} \boldsymbol{u}_{-} \boldsymbol{B}$ washed under air were not active (no conversion of oleylamine was observed) while nanoparticles $\boldsymbol{C} \boldsymbol{u} \_\boldsymbol{B}$ washed under argon with a modified procedure (see details in part 5.4 of the experimental section) were. $80 \%$ of 1 was transformed (see details of products formed below). Thus, nanoparticles surface should not be too oxidized in order to be able to transform 1 .

Catalytic transformation of oleylamine $\boldsymbol{l}$ in the above described conditions by $\boldsymbol{C} \boldsymbol{u}_{-} \boldsymbol{A}$ and $\boldsymbol{C} \boldsymbol{u} \_\boldsymbol{B}$ were then studied in details. When nanoparticles $\boldsymbol{C} \boldsymbol{u}_{-} \boldsymbol{A}$ were used as catalysts, the formation of two products can be identified from the ${ }^{1} \mathrm{H}$ NMR spectrum shown in Figure $\mathrm{S} 14$ : the secondary aldimine $\mathbf{3}$ and the conjugated secondary aldimine 4 . In this spectrum, two broad signals at $3.03 \mathrm{ppm}$ and at $4.27 \mathrm{ppm}$ were not attributed. Yields are given in Table 2. For catalysis with $\boldsymbol{C} \boldsymbol{u} \_\boldsymbol{B}$ nanoparticles, IR spectrum, ${ }^{1} \mathrm{H}$ NMR spectrum ESI-MS in Figure 5, Figure S14 and S15 confirms the formation of secondary aldimine $\mathbf{3}$ and conjugated secondary aldimine 4 , as for catalysis with $\boldsymbol{C} \boldsymbol{u} \_\boldsymbol{A}$. One peak at $260.2373 \mathrm{~m} / \mathrm{z}$ was obtained in mass spectrometry. We tentatively attributed it to a dehydrogenated derivative of oleylamine 1 . Two doublets at $3.25 \mathrm{ppm}$ and $2.46 \mathrm{ppm}$ were detected in the ${ }^{1} \mathrm{H}$ NMR of some 
catalytic experiments but were not attributed, neither were the wide and narrow peaks in the $1700-2200 \mathrm{~cm}^{-1}$ of the IR spectrum. Yields for catalysis with $\boldsymbol{C} \boldsymbol{u} \_\boldsymbol{B}$ are given in Table 2.

\begin{tabular}{|c|c|c|}
\hline & Catalysis $\boldsymbol{C u} \_\boldsymbol{A}(\%)$ & Catalysis $\mathbf{C u} \boldsymbol{B}(\%)$ \\
\hline 3 Secondary aldimine & 5 & Traces-5 \\
\hline 4 Conjugated secondary aldimine & Traces & $0-10$ \\
\hline 5 Nitrile & & Traces-20 \\
\hline 6 Secondary amine & & $15-20$ \\
\hline 7 Tertiary amine & & Traces-35 \\
\hline Non attributed product & 5 & Traces \\
\hline Conversior & 10 & $30-80$ \\
\hline
\end{tabular}

Table 2: ${ }^{1} \mathrm{H}$ NMR yield and oleylamine conversion (percent of initial product consumed) for catalytic experiment with CU_A and CU_B. "Traces" means that ${ }^{1} \mathrm{H}$ NMR yield was well below $5 \%$.

(A)

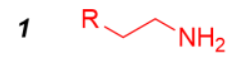

(B)

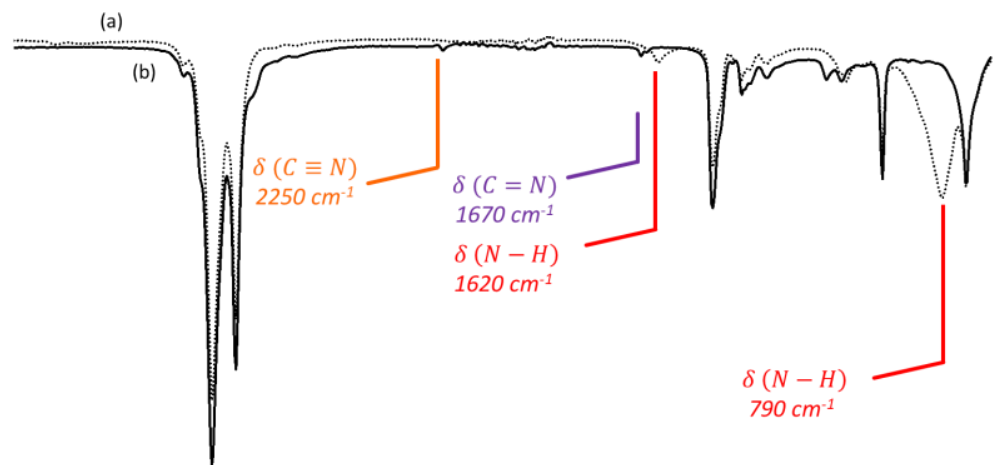

$3400320030002800 \quad 2600240022002000 \quad 1800 \quad 1600 \quad 1400 \quad 1200 \quad 1000 \quad 800 \quad 600$ Wavenumber $\left(\mathrm{cm}^{-1}\right)$
5<smiles>[R]CCNCC[R]</smiles>

(C)
6<smiles>[R]CCN(CC[R])CCCC</smiles>

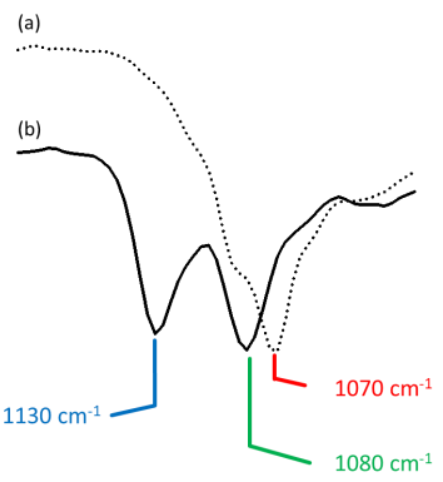

1200

Wavenumber $\left(\mathrm{cm}^{-1}\right)$

Figure 5: (A) Molecular structure of the species for which characteristics signals were detected by IR spectroscopy, (A) IR spectrum of (a) Commercial oleylamine, (b) Transformation of oleylamine catalysed by $C U_{-} B$ (C) Zoom of (A) in the carbon nitrogen simple bound stretching region (all the band attributed correspond to carbon nitrogen simple bound stretching). The colours of the line used to attribute IR spectra band in (B) and (C) refer to same coloured molecular structure in (A).

At this point, it is interesting to notice that the detected products formed during catalytic test with $\boldsymbol{C} \boldsymbol{u}_{-} \boldsymbol{A}$ and during the temperature plateau of the regular synthesis $\boldsymbol{A}$ are the same: secondary imine $\mathbf{3}$, conjugated secondary imine $\mathbf{4}$. It is also true for $\boldsymbol{B}$ : secondary aldimine $\mathbf{3}$, conjugated secondary aldimine 4 , nitrile 5 , secondary amine 6 and tertiary amine 7 . These 
results confirm that the nanoparticles formed during the temperature plateau are indeed responsible for the transformation of oleylamine and the formation of the related byproducts.

In order to clarify the nature of the active copper species, TEM micrographs of $\boldsymbol{C} \boldsymbol{u}_{-} \boldsymbol{B}$ and $\boldsymbol{C} \boldsymbol{u} \_\boldsymbol{A}$ after the catalytic experiment were performed (Figure S16). They showed an increase in nanoparticles polydispersity as a result of the catalysis experiment. Large objects, with characteristic sizes of $100 \mathrm{~nm}$ for $\boldsymbol{C} \boldsymbol{u}_{-} \boldsymbol{A}$ and $1 \mu \mathrm{m}$ for $\boldsymbol{C} \boldsymbol{u}_{-} \boldsymbol{B}$ were detected next to small objects of size below $10 \mathrm{~nm}$. We attribute these to Ostwald ripening occurring during the catalytic reaction. This suggests that molecular species containing copper were formed during the catalytic experiment. To verify that the nanoparticle surface was the catalytic site, rather than molecular species, the reaction crude of a catalytic test done with $\boldsymbol{C} \boldsymbol{u} \_\boldsymbol{B}$ was centrifuged and a catalytic test of oleylamine transformation with the supernatant was performed, following the methodology developed in our previous work. ${ }^{19}$ No conversion of oleylamine was observed. Even though the presence of transient active molecular species at high temperature cannot be excluded by this methodology, the more likely conclusion is that the copper nanoparticles are the active species.

To the best of our knowledge, only one example of transformation of amines in neat conditions (with the amine as reactant and solvent) catalysed by copper under inert atmosphere is found in the literature. The study conducted by the group of Hell deals with the activity of supported $\mathrm{Cu}(+\mathrm{II})$ catalyst for the dehydrogenation of benzylamine in neat conditions. $^{20}$ The only product formed was the aldimine N-benzylidenebenzylamine. These results are in line with activity found for $\boldsymbol{B}$, which shows selectivity for the aldimine.

Others reactions done in solvent give hints to understand difference of activity between $\boldsymbol{C} \boldsymbol{u} \boldsymbol{A}$ and $\boldsymbol{C} \boldsymbol{u} \_\boldsymbol{B}$. Catalytic activity of supported $\mathrm{Cu}(0)$ and $\mathrm{Cu}(+\mathrm{I}), \mathrm{Cu}(+\mathrm{II})$ solids and complexes was compared by the group of Mizuno for benzylamine reactivity in mesitylene at $140{ }^{\circ} \mathrm{C}$ 
under inert atmosphere. ${ }^{21}$ They found that $\mathrm{Cu}(0)$ is the only species active for the transamination reaction while $\mathrm{Cu}(0), \mathrm{Cu}(+\mathrm{I})$ and $\mathrm{Cu}(+\mathrm{II})$ can be active for dehydrogenation reaction. This result is consistent with the hypothesis that the inorganic surface of $\boldsymbol{C} \boldsymbol{u}_{-} \boldsymbol{A}$ is made of $\mathrm{Cu}(0)$ and these of $\boldsymbol{C} \boldsymbol{u} \_\boldsymbol{B}$ is made of oxidized copper, as $\boldsymbol{C} \boldsymbol{u} \_\boldsymbol{A}$ showed activity for both transamination and dehydrogenation reaction while $\boldsymbol{C} \boldsymbol{u}_{-} \boldsymbol{B}$ showed only reactivity for dehydrogenation reaction.

In the study of Mizuno, nitrile was formed only once when $\mathrm{Cu}$ supported on $\mathrm{Al}_{2} \mathrm{O}_{3}$ when DMSO was used as solvent. The group of Likhar also conducted benzylamine dehydrogenation to nitrile in DMF both with metallic copper and copper(II) oxide supported on alumina. ${ }^{22}$ Both catalyst were active for N-benzylidenebenzylamine formation and benzonitrile formation but the yield for nitrile was higher for $\mathrm{Cu}(0)(95 \%)$ than for $\mathrm{CuO}$ (43\%). These results are consistent with the higher activity of $\boldsymbol{C} \boldsymbol{u}_{-} \boldsymbol{A}$ compared to $\boldsymbol{C} \boldsymbol{u} \_\boldsymbol{B}$ for the formation of $\mathbf{5}$ and show that solvents play a significant role. In our experiments, neat conditions seems to amplify the difference of activity between $\mathrm{Cu}(0)$ and copper oxide for nitrile formation.

\section{Conclusion}

In this work, we studied the molecular reactions involved in the synthesis of $\mathrm{Cu}$ nanoparticles from $\mathrm{Cu}(\mathrm{OAc})_{2}$ and $\mathrm{Cu}(\mathrm{acac})_{2}$. The reaction of oleylamine with the acetate precursor produced higher amount of water than with the acetylacetonate one. Water released in the medium partly oxidized copper to copper oxide. This explained why the nanoparticles had different activity toward oleylamine transformation, both in the synthesis pot and in further catalytic experiment. Nanoparticles from $\mathrm{Cu}(\mathrm{OAc})_{2}$ catalysed the selective dehydrogenation to secondary aldimine 3 while nanoparticles from $\mathrm{Cu}(\mathrm{acac})_{2}$ catalysed the formation of many dehydrogenation and transamination products. This study underlines the relevance of careful 
precursor choice. They illustrate how a full analysis with both molecular and inorganic characterizations will promote a finer design of nanoparticles with controlled features for catalytic applications.

\section{Experimental section}

All syntheses and procedures were carried under inert gas $\left(\mathrm{N}_{2}\right.$ or $\left.\mathrm{Ar}\right)$ using an inert glovebox $\left(\mathrm{H}_{2} \mathrm{O}: \leq 0.1 \mathrm{ppm}, \mathrm{O}_{2}: \leq 0.1 \mathrm{ppm}\right)$ and Schlenk techniques. Oleylamine (98\%) and n-hexane for washing under inert atmosphere (anhydrous) were purchased from Sigma-Aldrich. Copper acetate (98\%, anhydrous) and Copper acetylacetonate (98\%, anhydrous) were respectively purchased from Alfa Aesar and Strem Chemicals and were characterized by XRD and energy dispersive X-ray spectroscopy (EDX). The results are shown in Figure S17 and Table S4. All products were used as received without further purification.

\subsection{Synthesis of copper nanoparticles with $\mathrm{Cu}(\mathrm{OAc})_{2}$ as precursor (referred as $\left.\mathrm{A}\right)$}

In a three necked round-bottom flask of $100 \mathrm{~mL}, 25.5 \mathrm{~g}$ of oleylamine (95.3 mmol, $9.3 \mathrm{eq}$. was added. The flask was put under vacuum 5 min and purged with $\mathrm{N}_{2}$ three times. Under $\mathrm{N}_{2}$, $\left[\mathrm{Cu}(\mathrm{OAc})_{2}\right](1.85 \mathrm{~g}, 10.2 \mathrm{mmol}, 1 \mathrm{eq}$.$) was dissolved in oleylamine to give a royal blue$ solution. The temperature was increased to $250{ }^{\circ} \mathrm{C}$ for $2 \mathrm{~h}$. The color changed from blue green, to brown around $180{ }^{\circ} \mathrm{C}$ to black around $200{ }^{\circ} \mathrm{C}$. The reaction crude was left to cool to room temperature. $510 \mathrm{mg}$ of powder were obtained (yield $=85 \%$ ) after washing. Washing procedure are described below.

\subsection{Synthesis of copper nanoparticles with $\mathrm{Cu}(\mathrm{acac})_{2}$ as precursor (referred as $\mathrm{B}$ )}

In a round-bottom flask of $100 \mathrm{~mL}$, oleylamine $(25.5 \mathrm{~g}, 95.3 \mathrm{mmol}, 9.3 \mathrm{eq}$. $)$ was added. The flask was put under vacuum 5 min and purged with $\mathrm{N}_{2}$ three times. Under $\mathrm{N}_{2},\left[\mathrm{Cu}(\mathrm{acac})_{2}\right]$ ( $2.55 \mathrm{~g}, 9.55 \mathrm{mmol}, 1$ eq.) was added and formed a pigeon blue gel. The temperature was 
increased to $250{ }^{\circ} \mathrm{C}$ for $2 \mathrm{~h}$. The color changed from pigeon blue, to deep-green to brown and to black. The reaction crude was left to cool to room temperature. $510 \mathrm{mg}$ of powder were obtained (yield $=85 \%$ ) after washing. Washing procedure are described below.

\subsection{Monitoring of organic products formed during syntheses $A$ and $B$}

The syntheses $\boldsymbol{A}^{\text {' }}$ and $\boldsymbol{B}$ ' were performed as regular $\boldsymbol{A}$ and $\boldsymbol{B}$ synthesis described above. Aliquots of $0.3 \mathrm{~mL}$ were taken in the reaction flask using a glass Pasteur pipet under a $\mathrm{N}_{2}$ gaz flow. A first series of aliquots was taken during the heating ramp when the temperatures reach $140{ }^{\circ} \mathrm{C}, 170{ }^{\circ} \mathrm{C}, 200{ }^{\circ} \mathrm{C}, 230{ }^{\circ} \mathrm{C}$ and $250{ }^{\circ} \mathrm{C}$. A second series was taken after $30 \mathrm{~min}, 1 \mathrm{~h}$ and $2 \mathrm{~h}$ of reaction after the temperature plateau was met. For synthesis $\boldsymbol{A}$ follow up, the aliquots were filtered on celite deposited on cotton in a Pasteur Pipette. For synthesis $\boldsymbol{B}$ follow up, the first series of aliquots were filtered as described above while the second series were centrifuged $\left(9,000 \mathrm{rpm}, 10 \mathrm{~min}, 20^{\circ} \mathrm{C}\right)$. The filtered or centrifuged aliquots were diluted in $\mathrm{CDCl}_{3}$ and ${ }^{1} \mathrm{H}$ NMR measurement were performed.

\subsection{Copper nanoparticles washing procedure under air}

After the reaction medium was cooled at R.T. under $\mathrm{N}_{2}$, $\mathrm{n}$-hexane $(20 \mathrm{~mL})$ was added to the crude solution. The crude was split in two centrifugation tube. Absolute ethanol $(20 \mathrm{~mL})$ was added in each tube and the tubes were vortexed. Then the nanoparticles were isolated by centrifugation $\left(9,000 \mathrm{rpm}, 10 \mathrm{~min}, 20^{\circ} \mathrm{C}\right)$. The supernatant was removed and the particles were redispersed in $\mathrm{n}$-hexane $(20 \mathrm{~mL})$ by sonication. Absolute ethanol $(20 \mathrm{~mL})$ was added in each tube and the tubes were vortexed. This operation was repeated once. The tubes were centrifuged $\left(6500 \mathrm{rpm}, 10 \mathrm{~min}, 20^{\circ} \mathrm{C}\right)$. The nanoparticles were then left to dry in air. For analysis on the liquid, an aliquot taken from the reaction crude was centrifuged at $(9000 \mathrm{rpm}$, $10 \mathrm{~min}, 20^{\circ} \mathrm{C}$ ). NMR ${ }^{1} \mathrm{H}$, IR, and MS were performed on the supernatant. 


\subsection{Copper nanoparticles washing procedure under inert atmosphere}

After cooling at R.T. under $\mathrm{N}_{2}$, the three-necked flask was sealed with adequate caps and taken into a glovebox. The crude was split in four centrifugation tubes and centrifuged $\left(6500 \mathrm{rpm}, 10 \mathrm{~min}, 20^{\circ} \mathrm{C}\right.$ ) within the glovebox. The supernatant was removed and the particles were redispersed in $\mathrm{n}$-hexane $(9 \mathrm{~mL})$ by simple shaking. The tubes were centrifuged (6500 rpm, $10 \mathrm{~min}, 20^{\circ} \mathrm{C}$ ). This operation was repeated once. The nanoparticles were left to dry in the glovebox atmosphere.

For NMR ${ }^{1} \mathrm{H}$, IR, and MS analyses on the liquid, aliquots were taken from the first centrifugation supernatant $\left(6,500 \mathrm{rpm}, 10 \mathrm{~min}, 20^{\circ} \mathrm{C}\right)$.

\subsection{Transformation of oleylamine catalyzed by copper nanoparticles $A$ or $B$}

Copper nanoparticles (49.5 mg, $0.75 \mathrm{mmol}, 1$ eq.) and oleylamine (5 mL, $15 \mathrm{mmol}, 20$ eq.) were added in flask of $25 \mathrm{~mL}$ flask in a glovebox. The flask was taken out of the glovebox, sonicated to disperse the nanoparticles and connected to a Schlenk ramp. The temperature was increased to $250{ }^{\circ} \mathrm{C}$ for $2 \mathrm{~h}$. For analysis on the liquid, the reaction crude was centrifuged at (6,500 rpm, $\left.10 \mathrm{~min}, 20^{\circ} \mathrm{C}\right)$. NMR ${ }^{1} \mathrm{H}$, IR, and MS were performed on the supernatant. For TEM analysis, the nanoparticles were then washed using the washing procedure under inert atmosphere described above adapted to the quantity of nanoparticles.

\subsection{X-ray diffraction on powder}

The X-ray diffraction patterns of dry powders were measured on a Bruker D8 diffractometer using $\mathrm{Cu} \mathrm{K \alpha}$ radiation at $1.5406 \AA$. Typical diffractogramms were collected with a step of $0.05^{\circ}$ with a scanning speed of 5 s/point. The backgrounds of the diffractogramms were subtracted with the EVA software. 


\subsection{Transmission Electron Microscopy}

A drop of a diluted solution of copper nanoparticles dispersed in pure hexane was allowed to dry on an amorphous carbon coated copper grid. TEM images were collected with a TWIN 120 (TECNAI SPIRIT) at $120 \mathrm{kV}$.

\subsection{Nuclear Magnetic resonance (NMR) spectroscopy}

${ }^{1} \mathrm{H}$ NMR spectra were recorded at room temperature on a Bruker Avance 300 spectrometer. The spectra of samples were performed diluted in $\mathrm{CDCl}_{3}$. Shifts $(\delta)$ are given in parts per million (ppm) using the resonance of the solvent peak as a secondary reference $\left(\delta\left({ }^{1} \mathrm{H}\right)=7.26\right.$ ppm for the residual signal of $\mathrm{CDCl}_{3}$ ).

\subsection{Fourier Transform Infra-Red spectroscopy}

Infrared spectra were collected on a Cary 630 FTIR spectrometer (Agilent Technologies) spectrometer equipped with ATR. One drop of the sample was deposited on the crystal. Transmittance was measured between $4000 \mathrm{~cm}^{-1}$ and $650 \mathrm{~cm}^{-1}$ every $4 \mathrm{~cm}^{-1}$.

\subsection{Electron spray ionization mass spectrometry (ESI-MS)}

Electron spray ionization mass spectroscopy was acquired using a mass spectrometer LC ESI/LTQ Orbitrap. For the ESI-MS analysis, $10 \mu \mathrm{L}$ supernatant was diluted in $1 \mathrm{~mL}$ of acetonitrile.

\subsection{Energy dispersive X-ray spectroscopy (EDS)}

A small amount of powder was deposited on a carbon adhesive tape on a Scanning Electron Microscope sample holder. EDX analyses were performed on a SEM HITACHI S-3400N at 
$18 \mathrm{kV}$. Cobalt was chosen as reference and analyses were performed on at least three different zones on the sample.

\section{Supplementary Information}

Additional XRD, ${ }^{1} \mathrm{H}$ NMR, ESI-MS and TEM data.

\section{Acknowledgements}

This project has received funding from the European Research Council (ERC) under the European Union's Horizon 2020 research and innovation programme (Grant agreement No. 758480). Sorbonne Université, CNRS and Collège de France are also acknowledged for support. Denis Lesage is acknowledged for his assistance with the ESI-MS measurements. Hélène Gérard and Nicolas Mézailles are acknowledged for helpful discussions regarding copper reactivity.

\section{References}

(1) Murray, C. B., Kagan.R., and B. M. G. Synthesis and Characterization of Monodisperse Nanocrystals and Close-Packed Nanocrystal Assemblies. Annu. Rev. Mater. Sci. 2006, 30 (June), 545-610.

(2) Qin, L. X.; Jing, C.; Li, Y.; Li, D. W.; Long, Y. T. Real-Time Monitoring of the Aging of Single Plasmonic Copper Nanoparticles. Chem. Commun. 2012, 48 (10), 15111513. https://doi.org/10.1039/c1cc14326c.

(3) Yeshchenko, O. A.; Dmitruk, I. M.; Alexeenko, A. A.; Dmytruk, A. M. SizeDependent Melting of Spherical Copper Nanoparticles Embedded in a Silica Matrix. Phys. Rev. B - Condens. Matter Mater. Phys. 2007, 75 (8), 1-6. https://doi.org/10.1103/PhysRevB.75.085434.

(4) Kanninen, P.; Johans, C.; Merta, J.; Kontturi, K. Influence of Ligand Structure on the Stability and Oxidation of Copper Nanoparticles. J. Colloid Interface Sci. 2008, 318 (1), 88-95. https://doi.org/10.1016/j.jcis.2007.09.069.

(5) Kister, T.; Monego, D.; Mulvaney, P.; Widmer-Cooper, A.; Kraus, T. Colloidal Stability of Apolar Nanoparticles: The Role of Particle Size and Ligand Shell Structure. ACS Nano 2018, 12 (6), 5969-5977. https://doi.org/10.1021/acsnano.8b02202.

(6) Kim, K.; Kim, K. L.; Shin, K. S. Co-Reduced Ag/Pd Bimetallic Nanoparticles: Surface Enrichment of Pd Revealed by Raman Spectroscopy. J. Phys. Chem. C 2011, 115 (30), 
14844-14851. https://doi.org/10.1021/jp203160z.

(7) Fedorov, A.; Liu, H. J.; Lo, H. K.; Copéret, C. Silica-Supported Cu Nanoparticle Catalysts for Alkyne Semihydrogenation: Effect of Ligands on Rates and Selectivity. $J$. Am. Chem. Soc. 2016, 138 (50), 16502-16507. https://doi.org/10.1021/jacs.6b10817.

(8) Pinna, N.; Garnweitner, G.; Antonietti, M.; Niederberger, M. A General Nonaqueous Route to Binary Metal Oxide Nanocrystals Involving a C-C Bond Cleavage. J. Am. Chem. Soc. 2005, 127 (15), 5608-5612. https://doi.org/10.1021/ja042323r.

(9) Oliva-Puigdomènech, A.; De Roo, J.; Kuhs, J.; Detavernier, C.; Martins, J. C.; Hens, Z. Ligand Binding to Copper Nanocrystals: Amines and Carboxylic Acids and the Role of Surface Oxides. Chem. Mater. 2019, 31 (6), 2058-2067. https://doi.org/10.1021/acs.chemmater.8b05107.

(10) Koziej, D.; Rossell, M. D.; Ludi, B.; Hintennach, A.; Novák, P.; Grunwaldt, J. D.; Niederberger, M. Interplay between Size and Crystal Structure of Molybdenum Dioxide Nanoparticlesâ-Synthesis, Growth Mechanism, and Electrochemical Performance. Small 2011, 7 (3), 377-387. https://doi.org/10.1002/smll.201001606.

(11) Vivien, A.; Guillaumont, M.; Meziane, L.; Salzemann, C.; Aubert, C.; Halbert, S.; Gérard, H.; Petit, M.; Petit, C. Role of Oleylamine Revisited: An Original Disproportionation Route to Monodispersed Cobalt and Nickel Nanocrystals. Chem. Mater. 2019, 31 (3), 960-968. https://doi.org/10.1021/acs.chemmater.8b04435.

(12) Carenco, S.; Labouille, S.; Bouchonnet, S.; Boissière, C.; Le Goff, X. F.; Sanchez, C.; Mézailles, N. Revisiting the Molecular Roots of a Ubiquitously Successful Synthesis: Nickel(0) Nanoparticles by Reduction of [Ni(Acetylacetonate) 2]. Chem. - A Eur. J. 2012, 18 (44), 14165-14173. https://doi.org/10.1002/chem.201201071.

(13) Frogneux, X.; Borondics, F.; Lefrançois, S.; D’Accriscio, F.; Sanchez, C.; Carenco, S. Surprisingly High Sensitivity of Copper Nanoparticles toward Coordinating Ligands: Consequences for the Hydride Reduction of Benzaldehyde. Catal. Sci. Technol. 2018, 8 (19), 5073-5080. https://doi.org/10.1039/C8CY01516C.

(14) Keil, P.; Lützenkirchen-Hecht, D.; Frahm, R. Investigation of Room Temperature Oxidation of $\mathrm{Cu}$ in Air by Yoneda-XAFS. AIP Conf. Proc. 2007, 882 (February 2007), 490-492. https://doi.org/10.1063/1.2644569.

(15) Choudhary, S.; Sarma, J. V. N.; Pande, S.; Ababou-Girard, S.; Turban, P.; Lepine, B.; Gangopadhyay, S. Oxidation Mechanism of Thin Cu Films: A Gateway towards the Formation of Single Oxide Phase. AIP $A d v . \quad$ 2018, $8 \quad$ (5). https://doi.org/10.1063/1.5028407.

(16) Carenco, S.; Labouille, S.; Bouchonnet, S.; Boissière, C.; Le Goff, X. F.; Sanchez, C.; Mézailles, N. Revisiting the Molecular Roots of a Ubiquitously Successful Synthesis: Nickel(0) Nanoparticles by Reduction of [Ni(Acetylacetonate) 2 ]. Chem. - A Eur. J. 2012, 18 (44), 14165-14173. https://doi.org/10.1002/chem.201201071.

(17) Staniuk, M.; Zindel, D.; Van Beek, W.; Hirsch, O.; Kränzlin, N.; Niederberger, M.; Koziej, D. Matching the Organic and Inorganic Counterparts during Nucleation and Growth of Copper-Based Nanoparticles - in Situ Spectroscopic Studies. CrystEngComm 2015, 17 (36), 6962-6971. https://doi.org/10.1039/c5ce00454c.

(18) Nene, A. G.; Takahashi, M.; Somani, P. R. Fe 3 O 4 and Fe Nanoparticles by Chemical Reduction of $\mathrm{Fe}(\mathrm{Acac}) 3$ by Ascorbic Acid: Role of Water Keywords Fe 3 O 4 Nanoparticles, Fe-Nanoparticles, Iron Oxide, Chemical Reduction Method. World J. Nano Sci. Eng. 2016, 6 (March), 20-28. 
(19) Frogneux, X.; Borondics, F.; Lefrançois, S.; D’Accriscio, F.; Sanchez, C.; Carenco, S. Surprisingly High Sensitivity of Copper Nanoparticles toward Coordinating Ligands: Consequences for the Hydride Reduction of Benzaldehyde. Catal. Sci. Technol. 2018, 8 (19), 5073-5080. https://doi.org/10.1039/c8cy01516c.

(20) Magyar, Á.; Hell, Z. Heterogeneous Copper-Catalyzed Coupling of Amines: A Possible Way for the Preparation of Imines. Monatshefte fur Chemie 2016, 147 (9), 1583-1589. https://doi.org/10.1007/s00706-016-1784-9.

(21) Kim, I.; Itagaki, S.; Jin, X.; Yamaguchi, K.; Mizuno, N. Heterogeneously Catalyzed Self-Condensation of Primary Amines to Secondary Amines by Supported Copper Catalysts. Catal. Sci. Technol. 2013, 3 (9), 2397-2403. https://doi.org/10.1039/c3cy00405h.

(22) Damodara, D.; Arundhathi, R.; Likhar, P. R. Copper Nanoparticles from Copper Aluminum Hydrotalcite: An Efficient Catalyst for Acceptor- and Oxidant-Free Dehydrogenation of Amines and Alcohols. Adv. Synth. Catal. 2014, 356 (1), 189-198. https://doi.org/10.1002/adsc.201300453. 


\section{Table of contents entry}

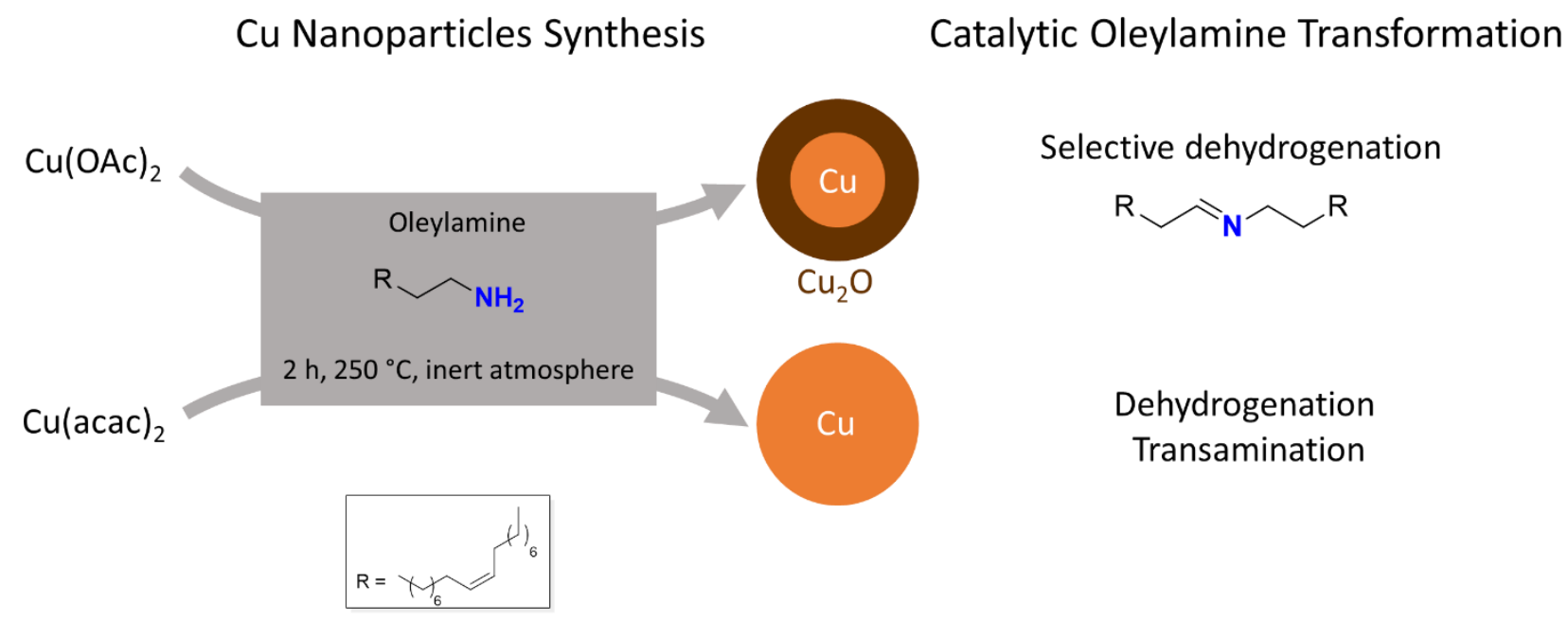

